\title{
Private medical care comes to Canada
}

T he Supreme Court's decision to strike down Quebec's laws prohibiting commerce in private health insurance should not be narrowly interpreted. By logical (and perhaps legal) extension, provincial laws that effectively prohibit physicians from practising in the private sector (through opt-out legislation, for example) are likely to be ruled invalid also. There is no use permitting private medical insurance but forbidding physicians to provide private care. Lawrie McFarlane, a former deputy minister of health for British Columbia, comments that the decision poses an "imminent threat of a two-tier system" (page 269). ${ }^{1}$

The Supreme Court ruling on what it judged a waiting time that was unreasonable and potentially harmful to a single patient is in fact a broad condemnation of medicare, a system that is failing to deliver despite recent federal injections of Can\$41 billion. Canada also ranks among the highest-spending nations on health care per capita. Is the problem simply insufficient resources, or is it, as Romanow, Kirby and others

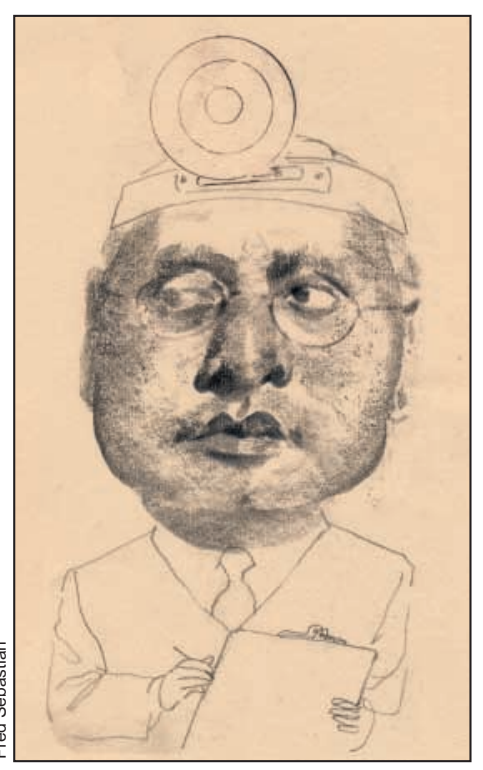

have reported, also, and perhaps mainly, inefficiency, mismanagement and professional self-interest? Physicians are at the vortex of the system and this crisis: Are we responsible?

In responding to the Supreme Court's decision, federal Health Minister Ujjal Dosanjh will have to make some tough decisions. But the provincial medical associations and the CMA also face complex and difficult challenges: the profession is deeply divided about two-tier health care. The case that triggered the Supreme Court decision was brought by a physician who was prohibited from opening a private health care facility. He is not alone among physicians. Others, however, are just as strongly committed to a single-tier system. In the face of such profound ambivalence, debate within the profession must be frank, not fogged with politeness and generalities. Steven Lewis, a health policy expert, lays out starkly the case that organized medicine is largely responsible for the crisis in medicare that resulted in the Supreme Court decision (page 275). ${ }^{2}$
Albert Schumacher, President of the CMA, defends the profession's record and outlines the perspective of the association and its members (pages 277). ${ }^{3}$

Responsibility and future roles aside, it is very likely, in our view, that a public-private mix of medical care will be the end result. What might it look like? With a two-tier system Canada would join Australia and countries in Europe and elsewhere where public and private health care coexist. We asked Richard Smith, former editor of $B M 7$ and now chief executive of UnitedHealth Europe, a company that markets private services in Europe to over 50 million people, to comment from both his long editorial experience and his current corporate viewpoint (page 273). ${ }^{4}$

Lastly, why did patient George Zeliotis have to wait so long for his elective orthopedic surgery before seeking recourse through the courts? What is wrong with waiting lists, particularly those for elective surgery? David Hadorn, former research director of the Western Canada Waiting List Project, considers questions of priority on waiting lists, reviews the widely divergent opinions of physicians, patients and the public on what constitutes a reasonable amount of time to wait and then outlines how the private sector can and likely will increase efficiency by, among other things, using nonphysician clinical assistants for some of the routine tasks common in elective surgery (page 271).

Private health care for elective surgical and some diagnostic procedures is certain to follow the Supreme Court decision. The high court allows no appeal. Let the grand experiment begin. - CMAJ

\section{References}

1. McFarlane L. Supreme Court slaps for-sale sign on medicare. CMA7 2005; 173(3):269-70

2. Lewis S. Physicians, it's in your court now. CMA7 2005;173(3):275-7.

3. Schumacher A. Doctors put patients first in health care debate. CMA7 2005; 173(3):277-8.

4. Smith R. The private sector in the English NHS: from pariah to saviour in under a decade. CMA7 2005;173(3):273-4.

5. Hadorn D. The Chaoulli challenge: getting a grip on waiting lists. CMAf 2005;173(3):271-3. 